
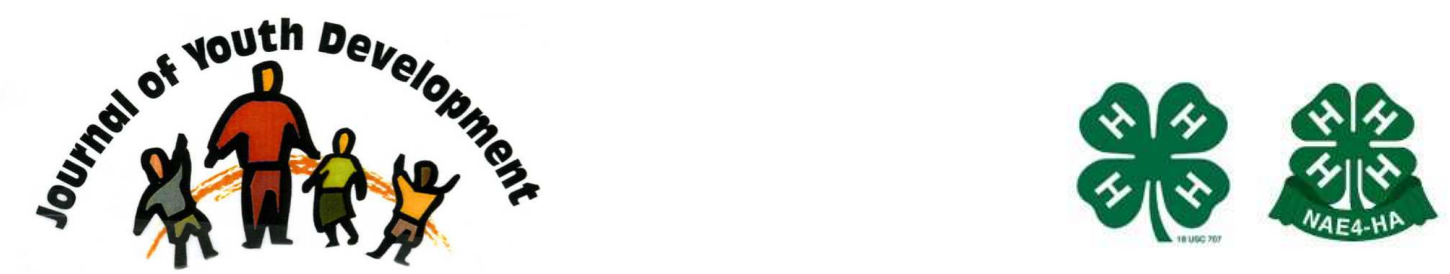

Bridging Research \& Practice

\title{
Developing a Life Skills Evaluation Tool for Assessing Children Ages 9-12
}

\author{
Kristina L. Luckey \\ Boise State University \\ kristinaluckey@u.boisestate.edu
}

Louis S. Nadelson

Boise State University 


\title{
JOURNAL OF YOUTH DEVELOPMENT \\ bridging research and practice
}

\section{Developing a Life Skills Evaluation Tool for Assessing Children Ages 9-12}

\author{
Kristina L. Luckey and Louis S. Nadelson \\ Boise State University
}

\begin{abstract}
Efforts that attend to the developmental needs of children, enhance their capacity to learn, and support their potential for becoming successful, have tremendous merit. Therefore, it is critical that steps are taken to evaluate the effectiveness of such endeavors. The purpose of this study was to create and validate a life skill outcomes instrument for use in extension youth programs. This instrument validation study utilized both quantitative and qualitative methodologies to establish the validity and reliability of a life skills instrument for nine to twelve year olds. The data collected from 111 participants suggests that the instrument is both valid and reliable for the intended age group. Study results, limitations, and ideas for future research are discussed.
\end{abstract}

\section{Introduction}

The 4-H Youth Development Program is a dynamic, out of school program that provides opportunities to support the developmental growth of youth ages eight to eighteen. The 4-H program is administered nationally by the United States Department of Agriculture, and locally by the Cooperative Extension Systems of land grant universities in each state and territory of the United States. It is estimated that 5.9 million youth participated in 4- $\mathrm{H}$ in 2007, making it the largest out of school youth development program in the world (4-H National Headquarters, 2001; Lerner, et al., 2008).

Governmental and other funding agencies frequently require youth service entities such as 4-H to measure and monitor the impact of their programs. The dearth of valid and reliable instruments for assessing the outcomes of these program make it difficult to achieve these requirements (National 4-H Headquarters, 2001). The lack of available instruments can impede 
the work of program administrators as they seek the data necessary to justify the continued promotion, funding and implementation of youth development programs (Bailey \& Deen, 2002; Pittman \& Cahill, 1992).

The goal of our study was to address the scarcity of instruments appropriate for assessing life skill outcomes of children nine to twelve participating in youth extension programs. Further, we sought to determine if items extracted from a web-based item repository could be effectively used to create such an instrument. We utilized processes of validation and applied rigorous testing to assure our instrument effectively and consistently assess the targeted outcomes. We balanced our aspirations for quality with the desire to assure our instrument was a practical and useful tool that youth development program administrators would consider for use when assessing program effectiveness.

We begin the presentation of our research with a discussion of the literature related to the history and development of life skills, the life skills evaluation tools that have been used to assess this process, and an over view of the WSU Cooperative Extension life skills evaluation system. We will then present our research questions and methodology, followed by a presentation of our analysis. We conclude our report with a discussion of implications, limitations, and further research suggestions.

\section{Life Skill Development}

Imbedded within the field of Positive Youth Development (PYD) is the vocabulary of life skills development. Life skills are defined as "skills that help an individual to be successful in living a productive and satisfying life" (Hendricks, 1996, p.4). The goals of many youth programs include creating opportunities for participants to experience the practical application of life skills so they may develop in these areas and become more readily able to utilize the skills later in life. For example, the National Cooperative Extension System, has developed a life skills model organized around the "4-H's" which are Head, Heart, Hands, and Health. These categories are embedded in the "Targeting Life Skills Model" as developed by Hendricks (1996) of the Iowa Sate University Cooperative Extension Service. These were developed with the notion that youth can be engaged in a wide range of beneficial and productive activities that encompass several life skills; it is the job of the practitioner to determine which life skills are most releveant and salient, and then evaluate their achievement accordingly (Hendricks, 1996).

\section{Life Skills Evaluation Tools}

Many organizations engage in program evaluation to determine if experiential based learning programs targeting the life skill development of youth have achieved their goals. However, to effectively evaluate the programs requires methods and tools with established reliability and validity. Due to the nature of our instrument development process we determined it to be prudent for us to review the literature that communicate how the validity and reliability has been established on life skill development assessment tools and especially those targeting children ages 12 and younger.

The American Camp Association (ACA) is an organization developed as a conduit for professionals who manage youth camps to collaborate, share knowledge, and promote child development through enhancing the quality of their camp experiences. The ACA provides a 
battery of evaluation tools to measure seven outcomes including: friendship skills, independence, teamwork, family citizenship, perceived competence, interest in exploration, and responsibility (American Camping Association, 2009). Three types of surveys were developed by ACA to measure intended outcomes. The "Camper Learning" survey was developed for campers" age 6-9 years of age and includes 14 questions measuring seven outcomes on a four-point Likert scale. The alpha reliability coefficient was .85. Random effects analysis of variance revealed no significant "interviewer" variations.

The "Basic Camp Outcomes" surveys were developed for campers ages 10-17. Seven surveys with 6 to 14 items were developed to measure each of the seven targeted camp experiences outcomes. Camp administrators can mix and match 6-14 of the indicators based on their programs and the areas of youth development they are seeking to assess. The seven instruments, which participants respond to on a five-point Likert scale, have established reliability coefficients exceeding .90, and all item-to-total correlations greater than .50 .

The "Detailed Outcomes" surveys are also composed of seven surveys that can be mixed and matched based on the outcomes that are to be assessed. These surveys were developed to measure both outcome gains resulting from camp experiences as well as how much of that gain is due specifically to camp. These six-point Likert scale inventories contain 6-14 indicators distributed across two subscales. The instrument developers report alpha reliability coefficients ranging from .87 to .93 . Criterion-related evidence of validity based on the matrix of correlations among the scale scores supported the use of these scales for their intended purpose (Statistical Information: Youth Camp Outcomes Questionaire, 2009).

Chambers and Johnston (2001) conducted a study to examine the developmental differences in childrens' use of rating scales. The study investigated the relationship between the developmental abilities in children ages 8-11 and their responses on self-report life skills evaluation tool. This study used the web-based Life Skills Evaluation System created by Washington State Cooperative Extension System and examined the validity of the life skill outcome indicators on children in grades three through five. The researchers recruited 65 youth attending a four-day 4-H camp. The evaluation tool consisted of 31 life skill indicators selected from the respository that addressed the following six life skills: decision making, wise use of resources, communication, accepting differences, healthy lifestyle choices, and selfresponsibility.

Due to the perceived complexity of the evaluation for children ages 8-11, the system's five-point Likert scale was reduced to a three-point scale. Research on the developmental differences of children ages 5-12 use of rating scales, reports that the younger children tend to report at higher extremes than older children (Chambers \& Johnston, 2001).

The researchers (Chambers \& Johnston, 2001) also chose to conduct a separate pre-test and post-test prior to and following the camp program. The web-based evaluation tool was orginally designed to administer the pre-test prior to the program and post-test following the program completion (Bailey \& Deen, 2002). However, the researchers chose this method of adminstration due to "the limited abstract reasoning skills of the younger age group, grades three to five (8 to 11)" (Loeser, Bailey, Benson, \& Deen, 2004; Piaget, 2002). Their analysis revealed a Cronbach's alpha internal reliability of .81 indicating a good level of instrument reliability. 
The research on life skills instruments use with children six to seventeen years of age indicate that the tools can adequately measure life skill outcomes on youth. However, there are limitations to relying exclusively on quantiative analysis for investigating the reliability and validity of these tools. Further, the results from these tools should be considered tentatively when investigating program delivery, and making modifications to optimize programs to enhance life skill development in participants nine to twelve. Therefore, in our study we utilized mixed methodologies to examine the instrument we developed to assess life skill development of nine to twelve year old youth. The instrument was composed of items extracted from a bank of items accessible through a web-based repository.

\section{Overview of the Web-based Life Skills Evaluation System}

Washington State Cooperative Extension was award a five-year State Strengthening Grant from the United Sates Department of Agriculture. These grants were awarded to:

1) Improve the statewide capacity to support community-based programs for children, youth, and families at risk; and

2) improve the quality and quantity of comprehensive community-based programs for children, youth, and families at risk.

In an effort to evaluate the effectiveness of the grant award recipients meeting the goals specified by the grant, Washington State Cooperative Extension created the Life Skills Evaluation System, a repository of life skill outcome indictors that can be used to assess life skill development of a range of developmental levels and program engagement (Bailey \& Deen, 2002).

The evaluation system repository was developed to provide program managers and evaluators access to items with established validity that could be used to develop program evaluation instruments. For example, the system provides a means for developing an instrument that could be used to test the assumption that Cooperative Extension 4- $\mathrm{H}$ Youth Development and Family Living programs teach life skills. Similarly, the system offers evaluators and researchers of 4-H programs an additional resource for creating valid instruments to measure growth in life skills. We capitalized on the availability and content of the evaluation system to develop an instrument to evaluate the life skill development of children 9-12 years old participating in 4-H programs.

\section{Establishing validity and reliability of the system}

Bailey and Deen (2002) established the validity of the life skill outcome indicators in the repository on two levels. First, during two regional program trainings Cooperative Extension personnel were asked to provide feedback on the items and suggestions on the feasibility and usefulness of the system for creating a range of instruments to assess life skill development of 4-H participants. Second, they utilized a peer-review process by Cooperative Extension specialists in three states outside Washington to evaluate assessment items and the corresponding system.

To establish the reliability of the instruments created by selecting indicators from the repository Bailey and Deen (2002) then conducted a pilot study which included nine Cooperative Extension 
personnel from Washington State who volunteered to administer a system-generated instrument with one of their family or youth programs. The Cronbach's alpha was applied to calculate the internal consistency of each of the life skill instruments. The reliability calculations produced results in the, "ranges from .75 to .91, indicating acceptable and high levels of internal consistency" (Bailey \& Deen, 2002, p.145). The results of these tests reveal the indicators selected from the repository can be assembled to form reliable instruments.

The reliability and validity of the indicators in the repository have been established using participants ages twelve and older. Our instrument validation study extends this work by selecting indicators from the repository and developing a life skill development instrument for use with participants' ages nine to twelve years old. The lack of research on younger participants (below the age of 12 years) provides justification for our research. Further, the likely involvement of nine to twelve year olds in 4-H programming provides additional justification for developing instruments that could be used to assess this group on the life skill development. Thus, the dearth of available instruments for assessing the life skill development of pre-adolescents and the need to measure program impact on this population provided the warrant for our research.

\section{Research Questions}

\section{Methods}

To study the development of life skills of students, nine to twelve years old, it is necessary to develop a valid and reliable instrument that will accurately assess participant perceptions of their competency on targeted life skill indicators. As previously discussed, the indicators contained within the Washington State University's (WSU) web-based Life Skills Evaluation System repository were originally developed to assess life skill outcomes for participants age 12 and older. Therefore, the validity and reliability of the indicators and subscales require further examination to justify the use of these indicators with participants younger than 12 years of age. The goal of our research was to establish the validity and reliability of a life skills development instrument for use with nine to twelve year old children. The following research questions guided this investigation:

- What is the reliability of a life skills instrument created using the Life Skills Evaluation System among students age nine to twelve?

- How did the individual items contribute to the overall reliability of the instrument?

- What do student interviews responses to Likert scale items contained within our life skills instrument reveal about the validity of the items for this age group?

\section{Data Collection and Analysis Methodology}

Participants and recruitment. University of Idaho Extension, Ada County, conducts 4-H programming for children ages 6-18. One of the modes of program delivery is through day camps from the months of June to August. Day camps vary from one three-hour session to three six-hour sessions. The intent for $4-\mathrm{H}$ programming is to provide participants with activities

that teach them life skills. The activities can be varied though out the year and are facilitated by instructors that have varying levels of education and experiences with children. Therefore, life skills in 4-H are implicitly taught through the participants experience. It is difficult to determine which specific life skills participants will gain at each individual day camp. These day camps provided the ideal setting and age group of participants to conduct this instrument validation 
study as their content and program delivery is reflective of the common 4-H program experience.

All participants in this study were selected from nine 4-H summer day camps. There were a total of 111 participants, $32 \%$ were age's eight to ten and $52 \%$ of the participants were eleven to thirteen years of age $(M=10.77, S D=1.29)$. The ethnicities of the participants were as follows: $70 \%$ Caucasian, 9\% racially mixed, 5\% Hispanic, 5\% American Indian, and 4\% Asian American with $7 \%$ of the participants left the section blank. Participants reported their home location which includes: $53 \%$ living in a community with a population of greater than 50,000 , $26 \%$ less than $50,000,5 \%$ rural, non-farm community, and $14 \%$ farm community. Given this sample diversity and age demographics, we determined it was appropriate for the intent of this study and proceeded with our analysis under the assumption that our participants were reflective of the target population.

\section{Methods}

The primary goal of our research was to establish the reliability and validity of a life skills instrument to be used with youth age nine to twelve. We conducted a cross sectional study using a combination of methodologies to gather both quantitative and qualitative data. We chose to use a combination of methodologies for the purposes of triangulation which, "seeks convergence, corroboration, and correspondence of results' across the different methods and will be used to increase the validity of constructs and inquiry results by counterbalancing known method biases and limitations" (Green, 2001, pgs. 252-253).

We conducted interviews with participants to triangulate results to establish the validity of our selected items. Of particular importance was the need to determine the readability of the items for the participating age group and to determine if the statements were comprehendible and accurately interpreted by the participants. We had decided it was necessary to gather the data to provide direction for making adaptations to the instrument's indicators, open-ended questions, and/or instrument format based on the readability of the items, the participants' interpretations of the indicators, and reliability coefficient of each indicator.

\section{Procedure}

Instrument Development. We constructed two life skill development instruments using the repository of life skill outcome indicators available from the WSU Cooperative Extension Life Skills Evaluation System. From the evaluation system we identified and extracted 30 life skill outcome indicators that were specifically designed to assess individual development on the following six life skills: communication, leadership, useful/marketable skills, self-responsibility, critical thinking, and positive identity. The validity of these items had not been established for our targeted population of nine to twelve year old participants.

We split the 30 indicators in such a manner to create two instruments: Form A and Form B. Each form had fifteen indictors that measured the six life skills. The instrument asked the participants to respond to indicators using a four point Likert scale ranging from "NO" to "YES." Item statements were similar to this one, "I can organize a group to reach its goals" which is intended to assess participants' leadership life skill. To make the Likert scale concrete and developmentally appropriate for the targeted population we utilized a combination of icons and words to represent the numerical scale. 
We sought to maintain a high level of consistency in the construction of the two forms by selecting an even number of indicators to each of the six life skills. Rather than grouping the indicators by life skill, we varied the indicators to reduce the possibility of participant trend responses. The full Form A instrument can be found in the Appendix.

Establishing Consent and Assent. We made arrangements with the 4-H summer camps director to mail consent/assent forms to the participants and their parents. Two weeks prior to start of the camps a reminder postcard was routinely sent to families who had enrolled a child in one of the camps which included information about the consent/assent documents.

Phone calls were made a day or two prior to the day camp to remind parents to return the consent/assent forms and to answer any questions they had about the life skills survey and the study. We were present the morning of each day camp to collect consent/assent forms and again answer any questions parents and children had about the project. We documented on a roster the participants who returned the consent and assent forms and were then eligible to participate in the evaluation.

Data Collection. Administration of the different forms was planned according to the number of participants based on the registration roster for each day camp so as to have approximately the same number of participants using the test for both forms. When data collection was completed 111 questionnaires were completed with 53 participants completing Form A and 58 completing Form B.

We used a retrospective pre-test and post-test which allowed us to calculate the reliability coefficient of the instrument based on a test-retest methodology. We took this approach as the camps were taking place at different times and for different durations. The approach simplified that data collection and minimized impact on the families involved in our project. To assure that the participants were informed, we directly administered the instrument at the day camps, described its purpose, and answered any questions participants asked about the process of completing the instrument. Participants were directed to first read the life skill indicator, to reflect on the life skill indicator prior to participating in the day camps and to fill out the section that reflects their level of having that life skill. Then they were instructed to reflect on their experience at their day camp and fill out the section indicating the level of life skill acquisition after having participated in the day camp. In an effort to ensure instrument completion accuracy, we monitored participants as they completed the instrument and reviewed each completed document as they were returned. Participants were given as much time as they needed to complete the instrument.

To triangulate the data, we conducted brief, five-minute interviews with consenting participants using a self-made life skills evaluation interview protocol/script (see Appendix). Participant interviews were conducted immediately following participants completing the questionnaire. We conducted one to three interviews on the final day of each day camp. Interviews were kept short from two to five minutes in length and were conducted in a separate location from their peers with a day camp staff member present for observation. There were 17 participants interviewed, nine females and eight males. Their ages included: One nine year old, seven ten year olds, two eleven year olds, and seven twelve year olds. Three nine year old females and one nine year old male signed the consent form for interviewing but when we asked them to 
participate they declined. Two audio recordings, one on a nine year old female and one on a 10 year old male, were lost due to recording interference from the weather at the River Camp.

We designed the interview questions to expose the participants' understanding of the vocabulary and concepts present in the existing indicators of the survey, specifically those that may have been difficult for participants of this age group to comprehend. Of primary concern were the younger participants' perceptions of vocabulary and concepts associated with the life skill terms: accurate, compare, leadership, contribute, commitments, following through on commitments, knowing sometimes one thing is better than another, settling disagreements, and organizing a group to reach a common goal. Determining the extent to which the participants understood these vocabulary and concepts is a critical step in establishing indicator validity.

Data Analysis. The quantitative portion in data analysis was conducted to determine the reliability coefficient on the instrument's life skills indicators. Therefore we chose to utilize the ANOVA to determine similarities between Forms A and B. To complete our quantitative analysis we calculated paired samples t-test to determine change to life skill perspective using the pre and post tests.

We selected two procedures to examine our quantitative data. The first was to compile and analyze the three open ended questions on our instrument to determine if the participants' answers provided evidence of life skill acquisition or other data indicating understanding useful to determining instrument validity. The second procedure involved coding the transcribed interviews conducted at each day camp with consenting participants. We coded the transcripts both deductively and inductively seeking to expose evidence of the participants' understandings of the vocabulary and concepts present in the instrument. We analyzed the data from the transcriptions of the 17 semi-structured interviews by creating a comparison chart that allowed us to readily expose emergent trends. We created this chart to identify which participants did or did not understand the vocabulary and/or concepts. To further tease apart the data we developed a color coding system to categorize participants as having a good understanding (yellow), an approximate understanding (green), or no understanding evident (blue).

Next, we quantified the coded data to help identify trends both by age of participants and by concepts of the participant's level of understandings of the vocabulary and concepts. Our quantification process was based on the scores we assigned to the participants based on their levels of understanding. For example, we scored the responses of the participants with a clear understanding with a " 3 ", those with an approaching understanding received a " 2 ", and no understanding were scored as " 1 ". To rate the participants' overall level of understanding of the vocabulary and concepts, we calculated the percentage of participants identified for each of the three categories for each of our codes.

\section{Results}

\section{Data Entry and Conditioning}

We have chosen to use the words "indicator" and "item" interchangeably for the following sections for descriptive analysis of the data. To begin our analysis we entered our collected data into a computer based statistical program to perform our instrument reliability and item analysis calculations. We then conditioned the data which included identifying eliminating incomplete 
surveys and those in which the participants' scores were identical from pre-test to post-test. The resulting working sample sizes were $N=41$ for Form $A$, and $N=47$ for Form $B$.

\section{Instrument Reliability}

Our first research question asked: What was the reliability of a life skills instrument created using the Life Skills Evaluation System among students ages nine to twelve? To answer this question we conducted a Cronbach's alpha reliability analysis on both Form A and Form B instruments. We used the post-test of each form for our calculations as it could be argued that the post-test is more likely to be representative of the participants' life-skill development than the retrospective pre-tests. The reliability analysis of Form A, $N=41$, revealed a Cronbach's coefficient alpha of .89 and for Form B, $N=47$, our Cronbach's coefficient alpha analysis of .90.

We used a repeated measures ANOVA to determine if there was a significant difference in the participants' responses from pre-test to post-test and to determine if there was a differential response between the participants using Form A and Form B. We entered the pre-test and posttest scores as the measured variable and the Form groups as the factor variable. The results indicated that there was a significant difference from pre-test to post test for time, $f(1,73)=$ $16.97, p<.01$, indicating that the participant answers changed from pre to post-test. The between groups analysis was not significant indicating that the participants did not differentially respond to the two forms of the instrument from pre-test to post test.

To determine if there were significant differences in the participants' response to the life skill items on the two forms we utilized an independent samples t-test with the pre-test scores as the variable and Form group as sample grouping. Our analysis failed to show significance which indicates that the participants answered similarly on Form A and Form B. This provides evidence that the participants were consistent in how they answered the instrument items and indicates that the two forms were similar in their assessment of life skills.

\section{Item Contribution}

Our second research question asked: How did the individual items contribute to the overall reliability of the instrument? To answer this question we conducted a correlation analysis of the post-tests for both questionnaire forms to calculate the point-biserial correlation values. We used these values to conduct our item analysis such as the contribution of each item to the overall reliability of the instrument.

Correlation analysis of Form A shows that the point-biserial correlation values (Threshold for significance $N=41$ is $r>$.308). There were two point-biserial values below the critical value, UMS2 and UMS4. Our content analysis of these items revealed them to have value in this life skill tool if the constructs of "useful/marketable skills" were explicitly taught to participants. Due to the items point-biserial values below the critical value, they could be removed from future assessments but would not significantly reduce the reliability of the instrument. The remaining items were all above the point-biserial critical value and therefore were answered consistent. 
Table 1

The Item Total Statistics for Form A

\begin{tabular}{|l|c|c|c|c|}
\hline $\begin{array}{c}\text { Item } \\
\text { Code }\end{array}$ & $M$ & SD & $\begin{array}{c}\text { Point } \\
\text { Biserial } \\
\text { Correlations } \\
(r)\end{array}$ & $\begin{array}{c}\text { Cronbach's } \\
\text { Alpha if } \\
\text { Item } \\
\text { Deleted }\end{array}$ \\
\hline P16 & 3.63 & .59 & .35 & .89 \\
\hline UMS2 & 3.61 & .55 & .26 & .89 \\
\hline C1 & 2.95 & 1.11 & .81 & .87 \\
\hline UMS4 & 3.61 & .68 & .28 & .89 \\
\hline UMS5 & 2.87 & .91 & .56 & .88 \\
\hline C2 & 3.58 & .68 & .44 & .89 \\
\hline SR2 & 3.18 & .98 & .79 & .87 \\
\hline L1 & 2.95 & 1.21 & .64 & .88 \\
\hline CT1 & 3.00 & 1.12 & .64 & .88 \\
\hline CT2 & 2.95 & 1.06 & .64 & .88 \\
\hline CT4 & 3.37 & .85 & .69 & .88 \\
\hline CT7 & 3.39 & .64 & .50 & .89 \\
\hline PI1 & 3.42 & .89 & .60 & .88 \\
\hline PI5 & 3.03 & 1.10 & .64 & .88 \\
\hline SR4 & 3.55 & .69 & .44 & .89 \\
\hline
\end{tabular}

Our calculations of the point-biserial correlation values for Form B are presented in Table 2 (Threshold for significance $N=47$ is $r>.308$ ). There were no point-biserial values significantly low enough to be concerned with removing indicators from Form $B$ of the instrument. Therefore each item contributes to the overall effectiveness to measure those constructs by this instrument.

Table 2

The Item Total Statistics for Form B

\begin{tabular}{|c|c|c|c|c|}
\hline $\begin{array}{c}\text { Item } \\
\text { Code }\end{array}$ & $\mathrm{M}$ & $\mathrm{SD}$ & $\begin{array}{c}\text { Point } \\
\text { Biserial } \\
\text { Correlations } \\
(r)\end{array}$ & $\begin{array}{c}\text { Cronbach's } \\
\text { Alpha if } \\
\text { Item } \\
\text { Deleted }\end{array}$ \\
\hline C3 & 3.20 & 1.01 & .70 & .89 \\
\hline C4 & 3.51 & .64 & .56 & .89 \\
\hline L1 & 3.24 & .94 & .68 & .89 \\
\hline L3 & 3.24 & .97 & .69 & .89 \\
\hline UMS1 & 3.41 & .81 & .83 & .88 \\
\hline UMS3 & 3.59 & .67 & .61 & .89 \\
\hline UMS6 & 3.15 & 1.22 & .57 & .90 \\
\hline SR1 & 3.49 & .75 & .67 & .89 \\
\hline
\end{tabular}




\begin{tabular}{|l|l|l|l|l|}
\hline SR3 & 3.76 & .49 & .35 & .90 \\
\hline CT3 & 3.59 & .63 & .46 & .89 \\
\hline CT5 & 3.54 & .67 & .73 & .89 \\
\hline CT6 & 3.54 & .74 & .46 & .89 \\
\hline PI2 & 3.66 & .62 & .55 & .89 \\
\hline PI3 & 3.59 & .59 & .54 & .89 \\
\hline PI4 & 3.39 & .80 & .35 & .90 \\
\hline
\end{tabular}

\section{Open Ended Question Responses}

Our third research question asked: What do student open ended questions responses to their camp experience reveal about their applications of Life Skills? To answer this question we examined the transcripts of the participant responses to our interview seeking indicators of understanding of life skill development and to expose evidence indicating they comprehended the survey items.

We began our analysis by examining the participants' responses to the three open-ended statements of our instrument. Again, the purpose of these statements was to glean further information from the participants about what they have learned and would like to see improved in the 4-H Day Camps. Typically, administrators of the 4-H Day Camps use the participants' responses to guide program delivery and content for the following year. For the purposes of instrument validation, we first examined the data to determine if participants responded to the open-ended questions, and if they had we then coded their responses for indicators of life skills content.

Out of the 111 questionnaires, $16 \%$ of the participants did not write any responses or wrote "none", "nothing", and/or "I don't know" to all three open-ended items. Twenty-four percent of the participants responded to all the statements. The first statement, "The most important thing I have gained from attending the 4-H Day Camps is..." had a $77 \%$ response rate. The second statement, "The one thing, if anything, I would change about the 4-H Day Camps is..." had a $50 \%$ response rate. The third statement, "Other comments I would like to make are..." had a $42 \%$ response rate. The variation in responses suggests that the participants' may have perceived these items from a range of perspectives.

Although we received responses to all three open-ended questions, participant responses to the first statement, "The most important thing I have gained from attending the 4-H Day Camps is..." were revealed to be the best evidence for life skill development. To communicate this finding we selected some representative responses to this question reflective of this condition. In addition, we matched the participant responses to the open ended question that to one of our life skills items and the corresponding life skill. Representative samples of these results are presented in Table 3. 
Table 3

Participant Responses and the Corresponding Life Skill Indicators

\begin{tabular}{|c|c|}
\hline Participant Response & $\begin{array}{c}\text { Life Skill Item } \\
\text { Corresponding Life Skill in Parentheses }\end{array}$ \\
\hline "How to be patient catching fish isn't easy" & $\begin{array}{c}\text { I work out problems as they are presented to } \\
\text { me. (Useful/Marketable Skills) }\end{array}$ \\
\hline "Learning to work with others" & $\begin{array}{l}\text { I contribute as a team member. } \\
\text { (Useful/Marketable Skills) }\end{array}$ \\
\hline "Following directions!" & $\begin{array}{l}\text { I follow instructions as they are given to me. } \\
\text { (Positive Identity) }\end{array}$ \\
\hline "Cooking skills \& Social skills" & I enjoy using my skills. (Positive Identity) \\
\hline $\begin{array}{l}\text { The thought everything I do may decide the } \\
\text { fate of the world." }\end{array}$ & $\begin{array}{l}\text { I do things for myself and for others. (Positive } \\
\text { Identity) }\end{array}$ \\
\hline "I can make a big difference." & $\begin{array}{l}\text { I have control over my own personal } \\
\text { goals/future. (Self-Responsibility) }\end{array}$ \\
\hline
\end{tabular}

The examination of our participants' responses to the open-ended survey items provides further support for the developmental appropriateness of the Likert scale items. Further, these responses provide additional empirical evidence of the participants' applications and acquisition of Life Skills.

\section{Participant Interviews Responses}

Our fourth research question asked: What do student interviews responses to Likert scale items contained within my life skills instrument reveal about the validity of the items for this age group? To answer this question we coded the participants' responses to interview questions in an effort to expose evidence of vocabulary and concepts that may have been problematic such as challenging to comprehend or misinterpreted. Our results are first presented by age level of participant and then by cumulative response to the vocabulary associated with the seven life skill concepts.

Response by Age. Six out of the seven twelve year old participants understood all of the vocabulary and concepts and were able to provide rich description of them when asked to clarify the meanings of the terms or ideas. The ten and eleven year olds varied in how descriptive they were in their responses, however, four out of the seven of the ten year old participants from this group provided responses that indicated understandings of the vocabulary and concepts. Both of the eleven year olds provided evidence of understanding the vocabulary and concepts with a few exceptions. One of our eleven year old participants did not know what "accurate" meant and the other eleven year old participant had difficulty providing an example of "organizing a group to reach a goal." The following excerpt, an interaction with an 11 year old female 4-H Day Camp participant, provides an account of the kinds of interactions that took place during the interviews: 
Interviewer: "Have you ever organized a group to reach a goal?"

Participant 8: "Um, I think so?"

Interviewer: "How did you do that?"

Participant 8: Participant shrugged shoulders.

Interviewer: "Have you ever seen someone organize a group of people to reach a goal?" Participant 8: "Yes."

Interviewer: "And what kinds of skills, what kinds of things do you do to get everybody to reach a goal?"

Participant 8: "Have the same opportunity (...) practice being with a lot of kids."

This interaction may suggest that the participant is not clear about what is involved when organizing a group. In contrast, a nine year old male participant communicated understanding of "leadership" and "contribute" of the nine vocabulary and concepts. The following excerpt provides the documentation for understanding of leadership:

Interviewer: "Think of someone that is a great leader. It can be you, a friend, a President, anyone. What makes them a good leader? How do you know they are a great leader?"

Participant 9: "My mom and my dad because they are always helping me." Interviewer: "Are there other ways that can make someone a good leader?" Participant 9: "Like telling what not to do and what to do."

The following excerpt provides the documentation for understanding of contribute: Interviewer: "Have you ever been on a team? What does it mean to contribute to a team?"

Participant 9: "Yes. Be a good teammate and take turns. Like if you're on basketball, pass the ball."

Although the participant involved in the presented interview may be representative of his/her peers we must maintain caution in suggesting that the responses are typical of the other nine year olds participating in our study. Further investigation involving more nine year olds would be necessary to make valid claims for inferring representation of our data.

Our analysis of the interview transcripts by age revealed the concepts "comparison" and "organizing a group" to be the most challenging for the participants to comprehend and articulate (see Figure 3). Our analysis also revealed the proportionally our age nine and ten participants were less able to describe or give an example of "comparison" than their eleven and twelve year old peers. Further analysis also revealed that in general the participants' had constrained abilities to communicate understanding of the concepts associated with organizing a group. 
Figure 1

The participants' level of understanding of major life skill concepts deliniated by age.

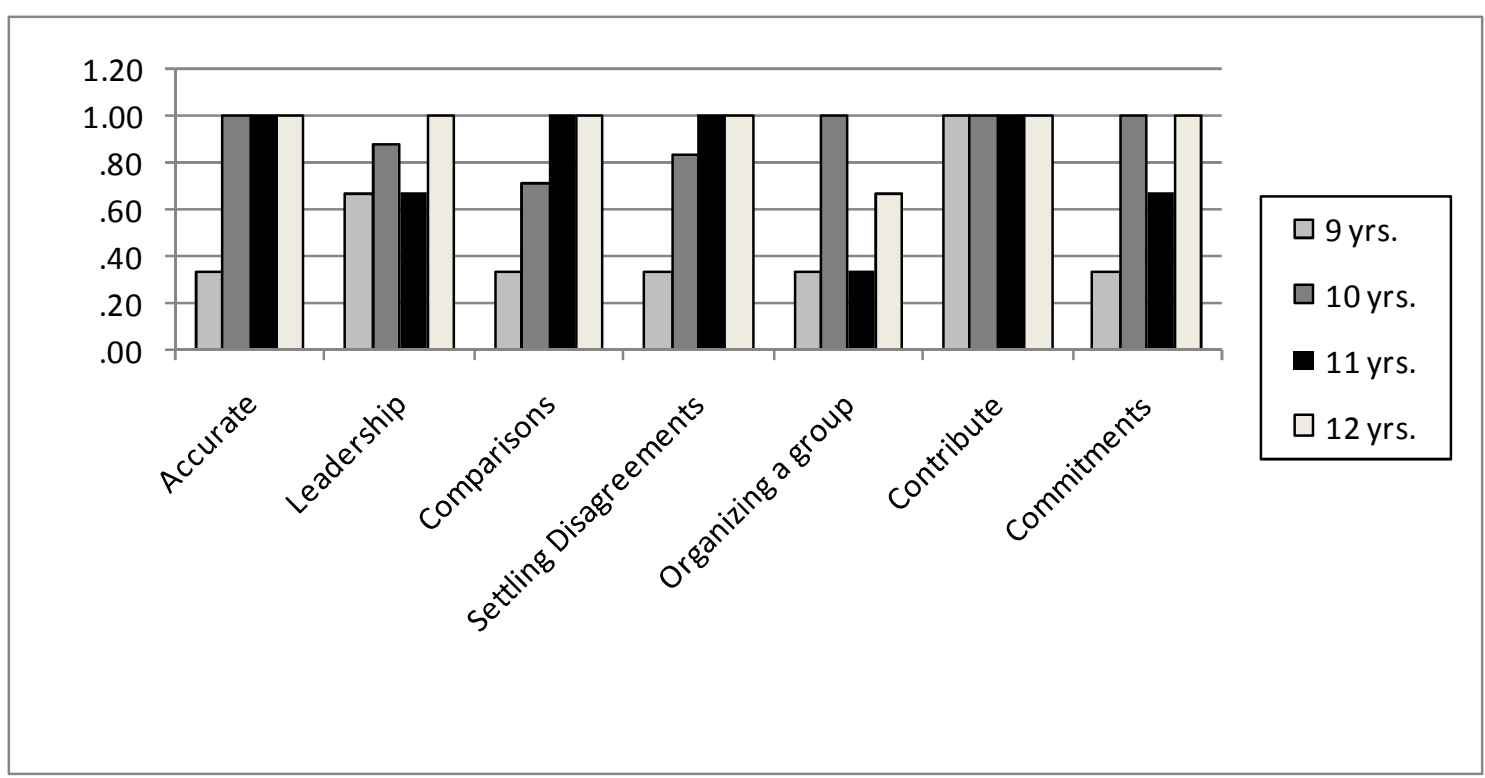

Group Understandings of Concepts. As we continued our analysis of interview transcripts it became apparent the there were certain life skill concepts that all participants struggled to provide a clear understanding in their responses. With the exception of two concepts, $75 \%$ or more of the participants were able to articulate meaningful explanations of the targeted concepts. For the remaining two concepts only about half the participants could provide adequate communication of understanding. The first life skill concept that we identified as potentially overly complex was "comparing." This was made apparent as participants struggled to adequately share a time they had to "compare ways of doing something." Fifty-five percent of the participants that answered this question demonstrated a clear understanding. A similar approach was used as we attempted to determine participants' perceptions of the concept "organizing a group." as we asked, "Have you ever organized a group to reach a goal and how did you do that?" Again fifty-five percent of the participants answered this question with a response that could be interpreted as reflective of a clear understanding of the concept. The results for the analysis by life skill concept are presented in Table 4. 
Table 4

Percentage of Participants Understandings of Concepts

\begin{tabular}{|c|c|c|c|}
\hline Concepts & Clear Understanding & $\begin{array}{c}\text { Approaching } \\
\text { Understanding }\end{array}$ & No Understanding \\
\hline Accurate & $91 \%$ & - & $9 \%$ \\
\hline Leadership & $82 \%$ & $9 \%$ & $36 \%$ \\
\hline Comparisons & $55 \%$ & $9 \%$ & $18 \%$ \\
\hline Settling Disagreements & $73 \%$ & $9 \%$ & $27 \%$ \\
\hline Organizing a Group & $55 \%$ & $18 \%$ & - \\
\hline Contribute & $100 \%$ & - & $9 \%$ \\
\hline Commitments & $82 \%$ & $9 \%$ & \\
\hline
\end{tabular}

\section{Discussion}

Many challenges in assessing children life skill development occur due to their transition between stages of development from ages 9-12 (Boeree, 2006; Chambers \& Johnston, 2001; Piaget, 2002;). In this research we attempted to address this issue, by developing a life skills assessment and then testing it empirically using a range of methods. Our results indicate the Life Skills Instrument that we developed for assessing 9-12 year old students is valid for assessing this populations' life skill development.

Our quantitative analysis of participants' responses to From A and Form B did not vary which indicates a number of items selected from the repository may be used to capture life skill development. Further, our analysis indicates that the items reliably and consistently measured life skill perceptions. Our independent samples t-test results indicate that one could potentially select from a range of indicators from the repository to create a valid measure of life skill outcomes for the 9-12 year old population. In addition, our results indicate that the altering or mixing of indicators does not compromise the validity and reliability of the life skill measures for this participant population.

However, our data also revealed elements of the instrument that may be potentially problematic. Only fifty-five percent of the interviewed participants were able to give a description or an example of the "organizing a group" and "comparing," concepts. We posit two possibilities for this result. The first possibility is that the participants, due to their present developmental stage, have difficulty in constructing an example of what it means to compare. According to Piaget's developmental theories, children from ages seven to around eleven tend to operate in the "concrete operations stage" (Boeree, 2006; Piaget, 2002). Children in this stage can compare items but may have difficulty being asked to reflect back to an example of when they had to compare something. Most of the ten and eleven year olds had more success in providing an example when prompted with a case related to school such as in comparing objects' weights or shapes. Since children around the age of twelve and older are more likely to be developmentally able to work within a "formal operational" (Boeree, 2006; Piaget, 2002) 
they are antitipated to have increased compacity to adequately explain abstract concepts, a condition that we exposed in our analysis. Our analysis of the interviews revealed all but one of the twelve year olds was able to describe and elaborate in detail an example of both comparing and organizing a group. The second reason may lie in the participants' lack of real-world opportunity to practice the skills being measured (i.e. organizing a group or comparing). Regardless, our analysis did reveal the instrument was effective, but data should be considered within the context of the developmental stages of the participants completing the surveys.

\section{Implications}

This life skills evaluation tool for participants ages 9-12 can be utilized to effectively measure life skill outcomes using the WSU Cooperative Evaluation System repository for the following life skills: communication, leadership, useful/marketable skills, self-responsibility, critical thinking, and positive identity. Participant responses to open-ended prompt and our interview data corroborate our conclusion that life skill development of children ages 9-12 can be successfully assessed. Further, since our data was drawn from participants engaging in a range of programs promoting life skill development there is indication that the items may transcend context and assess the constructs independent of the specific experience.

\section{Limitations}

There were several limitations to our study. First, is the distribution of the participants by age that we interviewed, which included a scant number of nine year olds. This is reflective of the challenges associated with recruitment of this group. We had four consenting nine year olds to interview, but when we approached them some acted like they were intimidated by the interview process and declined. Therefore, our input from more nine year olds may result in different outcomes. The focus on this younger age group is certainly an excellent direction for future life skill assessment research.

Second, because of our desire to follow the format of extant instruments we constructed the age section of our demographic questionnaire to include only three age options (i.e. 8-10, 1113 , and 14-16). We recognized this as a problem with our age constrained population (9-12 year olds) after the second day of data collection and changed the section to allow participants to select their exact age. However, we were unable to delineate the ages of the participants completing the questionnaires and had to analyze the data in the two age range groups of 8-10 and 11-13. Therefore, we were unable to identify and analyze the data according to participants' distinct ages. Although we certainly had a large enough sample to limit the impact of this process, additional data collection by specific age level is certainly warranted in future investigations.

Third, many of the participants repeated the day camps and completed a questionnaire at each day camp. This may have been problematic as some of the repeating participants may not have wanted to take the survey again or might have completed the survey quickly without full attention to the item content. However, we feel that the interviews substantiated the expectation that the students could understand the content and were capable to accurately responding giving the time and encouragement to do so. Further evaluation of the implications of repeated completion of the surveys in conjunction with different camp settings is an excellent direction for future research. 


\section{Conclusion}

Youth development programming can provide a wide variety of opportunities for children ages 9-12 to develop life skills (Lerner \& Lerner, 2008). Our research verified the ability to use a repository of life skill outcome indicators to measure the construct development in this population. It is our hope that others will capitalize on our methods to meet the ongoing goal of "providing an instrument with rigorous research integrity" (National 4-H Headquarters, 2001) that can be used by program administrators to assess the impact of their offerings on youth life skill development.

\section{References}

Bailey, S.J., \& Deen, M.Y. (2002). Development of a Web-based Evaluation System: A tool for measuring life skills in youth and family programs. Family Relations, pp. 138-147.

Benson, P.J., Scales, P.C., Stephen, H.F., \& Sesma, Jr., A. (2006, November). Positive Youth Development So Far: Core hypotheses and thier implications for policy and practice. Insights \& Evidence, pp. 1-13.

Catalano, R.F., Berglund, L.M., Ryan, J.A., Lonczak, H.S., \& Hawkins, J.D. (2004). Positive Youth Development in the United States: Research Findings on Evaluations of Positive Youth Development Programs. The ANNALS of the American Academy of Political and Social Science, pp. 591, 98-124.

Chambers, C.T., \& Johnston, C. (2001). Developmental Differences in Children's Use of Rating scales. Journal of Pediatric Psychology , 27, 27-36.

Boeree, C.G. (2006). Personallity Theories: Piaget. Retrieved September 14, 2009, from Shippensburg University: http://webspace.ship.edu/cgboer/piaget.html

Damon, W. (2004). What Is Positive Youth Development? The Annuals of the American Academy of Political and Social Science , 591, 13-24.

Dewey, J. (1938). Experience \& Education. New York: Touchstone.

Dryfoos, G.J. (1990). Adolescents at Risk. New York: Oxford University Press.

Green, J.C. (2001). Mixing Social Inguiry Methodologies. In V. Richardson(Ed.), Handbook of Research on Teaching (4 ${ }^{\text {th }}$ Ed., pp. 251-258). Washington, DC: American Educational Research Association.

Hendricks, P. (1996). Develping Youth Curriculum Using the Targeting Life Skills Model: Incorporating developmentally appropriate learning opportunities to assess impact of life skill development. Ames, Iowa: Iowa State University. 
Gronlund, N.E. (1993). How to Make Achievement Tests and Assessments. MA: Allyn \& Bacon Publishing.

IES National Center for Education Statistics. (n.d.). Retrieved August 13, 2009, from Digest of Education Statistics: http://nces.ed.gov/programs/digest/d08/tables/dt08 002.asp

Kolb, D. (1984). Experiential Learning: Experience as the source of learning and development. Englewood Cliffs, NJ: Prentice Hall, Inc.

Lerner, R.M., \& Lerner, J.V. (2008). The Postive Development of Youth. Medford, Massachusetts: Tufts University.

Lerner, R. (2005). Promoting Positive Youth Development: Theoretical and empirical bases. White paper prepared for the Workshop on the Science of Adolescent Health and Development, National Research Council/Institute of Medicine. Washington, DC: National Academies of Science.

Loeser, D.H., Bailey, S.J., Benson, R.L., \& Deen, M.Y. (2004, August). Measuring Impacts with Young Audiences: Adapting a Life-Skills Instrument for Use with Third to Fifth Grade Youth. Retrieved June 12, 2009, from Journal of Extension: http://www.joe.org/joe/2004august/rb1.php

McLellan, J., \& Youniss, J. (2003). Two Systems of Youth Service: Determinants of voluntary and required youth community service. Journal of Youth and Adolescence, 32,47-58.

National 4-H Headquarters. (2001). Prepared and Engaged Youth: National 4-H impact assessment project. Washington, DC: National 4-H Headquarters.

Pfeiffer, J.W., \& Jones, J.E. (n.d.). Retrieved December 3, 2008, from: http://www.experientiallearning.ucdavis.edu/module1/el1 40-5step-definitions.pdf

Piaget, J. (2002). The Language and Thought of the Child (Reprint of 3rd ed., c1959 ed.). New York: Routledge.

Pittman, K.J., \& Cahill, M. (1992). Pushing the Boundaries of Education: The implications of a youth development approach to education policies, structures and collaborations. Washington, D.C.: Academy for Educational Development.

Rhodes, J., Grossman, J., \& Resch, N. (2000). Agents of Change: Pathways through which mentoring relationships influence adolescents' academic adjustment. Child Development, 71, 1662-1671.

Statistical Information: Youth Camp Outcomes Questionaire. (2009, June). Retrieved June 24, 2009, from American Camp Association, Inc.:

http://www.acacamps.org/members/outcomes/statistical information.php

SPSS Inc. (1990). Chicago, Ill: SPSS Inc. 
Tierney, P., Grossman, J.B., \& Resch, N.L. (1995). An Impact Study of Big Brothers/Big Sisters. Philidelphia, PA: Public/Private Ventures.

U.S. Department of Education: Policy. (1980). Retrieved November 16, 2008, from ED.Gov: http://www.ed.gov/policy/elsec/leg/esea02/pg1.html

US Department of Education. (2009, January 16). Retrieved August 8, 2009, from ED.gov: http://www.ed.gov/admins/lead/account/saa.html\#letters

Way, N., \& Robinson, M. (2003). A Longitudinal Study of the Effects of Family, Friends, and School Experiences on the Psychological Adjustment of Ethnic Minority, Low-SES Adolescents. Journal of Adolescent Research , 324-346.

(C) Copyright of Journal of Youth Development Bridging Research and Practice. Content may not be copied or emailed to multiple sites or posted to a listserv without copyright holder's express written permission. However, users may print, download or email articles for individual use. 


\section{Appendix A}

\section{4-H Day Camps Survey}

We want to know how well the 4-H Summer Day Camps program works. We are asking you to answer the following questions about what you may have learned from being in the 4-H Day Camps. It should take about 10 minutes of your time to complete the survey. You do not have to fill out this survey. If you decide not to fill out the survey, it will not affect your participation in future UI Extension 4-H Youth Development programs. Your answers will be anonymous and will not be identified in any way. This means that no one will know how you have answered any of the questions. Answering the questions means you agree to participate in this survey. If you have any questions about this survey or the evaluation, please contact Brian Luckey or Kristina Luckey.

\begin{tabular}{|c|c|c|c|}
\hline \multicolumn{4}{|c|}{ Tell us about yourself. (Check one response to each question). } \\
\hline $\begin{array}{c}\text { 1. My age is: } \\
-8 \\
-9 \\
-10 \\
11 \\
-12 \\
-13 \\
14 \\
-15 \\
16\end{array}$ & $\begin{array}{r}\text { Girl } \\
\text { Boy }\end{array}$ & $\begin{array}{l}\text { 3. My current home is a: } \\
\text { farm } \\
\text { rural non-farm } \\
\text { town under } 50,000 \\
\text { city over } 50,000 \\
\text { 4. I Live in: County }\end{array}$ & $\begin{array}{c}\text { 5. I would describe } \\
\text { myself as: } \\
\text { African American } \\
\text { American Indian } \\
\text { Asian American } \\
\text { Hispanic } \\
\text { White/Caucasian } \\
\text { Racially mixed }\end{array}$ \\
\hline
\end{tabular}

1. The most important thing I have gained from attending the 4-H Day Camps is

2. The one thing, if anything, I would change about the 4-H Day Camps is

\section{Other comments I would like to make are}




\begin{tabular}{|c|c|c|c|c|c|c|c|c|}
\hline \multirow{3}{*}{$\begin{array}{c}\text { Because of my participation } \\
\text { in the } \\
\text { 4-H Day Camp: }\end{array}$} & \multicolumn{4}{|c|}{$\begin{array}{c}\text { Back . . . before I participated in } \\
\text { the 4-H Day Camps. }\end{array}$} & \multicolumn{4}{|c|}{$\begin{array}{c}\text { Now. . . after I have } \\
\text { participated in the 4-H Day } \\
\text { Camps. }\end{array}$} \\
\hline & \multicolumn{4}{|c|}{$\begin{array}{c}\text { Circle one number for each } \\
\text { statement. }\end{array}$} & \multicolumn{4}{|c|}{$\begin{array}{c}\text { Circle one number for each } \\
\text { statement. }\end{array}$} \\
\hline & No : & Sometimes & $\begin{array}{c}\text { Usually } \\
;\end{array}$ & Yes & $\begin{array}{l}\text { No } \\
:\end{array}$ & Sometimes & $\begin{array}{c}\text { Usually } \\
-;\end{array}$ & Yes \\
\hline $\begin{array}{l}\text { 1. I know that I am good at } \\
\text { doing one or more things. }\end{array}$ & : & $\odot$ & ;) & 0 & (8) & $(-)$ & (;) & 0 \\
\hline $\begin{array}{l}\text { 2. I follow instructions as they } \\
\text { are given me. }\end{array}$ & (:) & ; & ;) & 0 & (2) & $\oplus$ & (:) & 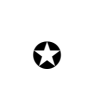 \\
\hline 3. I can make a presentation. & : & 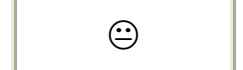 & ;) & $\boldsymbol{\theta}$ & (2) & 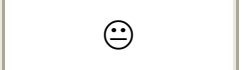 & ;) & $\boldsymbol{\theta}$ \\
\hline $\begin{array}{l}\text { 4. I accept responsibility for } \\
\text { doing a job. }\end{array}$ & : & $\odot$ & ;) & 0 & (8) & $\odot$ & (:) & 0 \\
\hline $\begin{array}{l}\text { 5. I keep accurate and useful } \\
\text { records. }\end{array}$ & : & 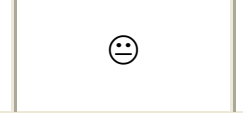 & ;) & $\boldsymbol{\Delta}$ & (8) & $\oplus$ & (:) & 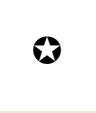 \\
\hline $\begin{array}{l}\text { 6. I listen carefully to what } \\
\text { others say. }\end{array}$ & : & $\odot$ & (:) & 0 & :) & $\oplus$ & (:) & 0 \\
\hline 7. I admit to mistakes I make. & : & $\odot$ & (:) & $\boldsymbol{\theta}$ & (8) & $\odot$ & (:) & 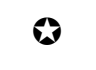 \\
\hline $\begin{array}{l}\text { 8. I use different leadership } \\
\text { styles. }\end{array}$ & : & $\oplus$ & (:) & 0 & : : & $\oplus$ & (;) & 0 \\
\hline $\begin{array}{l}\text { 9. I try doing the activities } \\
\text { more than one way. }\end{array}$ & :) & $\oplus$ & (:) & 0 & :) & $\oplus$ & (:) & $\theta$ \\
\hline $\begin{array}{l}\text { 10. I compare one way of doing } \\
\text { things with another way. }\end{array}$ & : & $\odot$ & (:) & 0 & (2) & $\oplus$ & (:) & 0 \\
\hline $\begin{array}{l}\text { 11. I can decide how to do a } \\
\text { job after getting directions. }\end{array}$ & : & $\oplus$ & (:) & 0 & :) & $\oplus$ & (;) & 0 \\
\hline $\begin{array}{l}\text { 12. I know that sometimes one } \\
\text { thing is better than another. }\end{array}$ & : & $\odot$ & ;) & 0 & (8) & $\oplus$ & ;) & 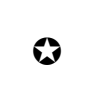 \\
\hline $\begin{array}{l}\text { 13. I feel like I have control } \\
\text { over some things in my life. }\end{array}$ & : & $\odot$ & ;) & 0 & :) & $\oplus$ & (;) & 0 \\
\hline $\begin{array}{l}\text { 14. I can decide what I want to } \\
\text { do. }\end{array}$ & :) & $\odot$ & (:) & 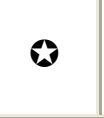 & :) & $\oplus$ & (:) & $\theta$ \\
\hline $\begin{array}{l}\text { 15. I have control over my own } \\
\text { personal goals/future. }\end{array}$ & : & $\odot-$ & ;) & 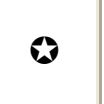 & (2) & $\oplus$ & ;) & 0 \\
\hline
\end{tabular}




\section{Appendix B}

Life Skills Evaluation Interview Protocol/Script:

"Hi! My name is Mrs. Luckey. How are you? Did you have fun in your day camp? You just took a survey about today's day camp. I want to make the survey easy to take. I would like to ask you some questions about the survey you just took? Now there is no right or wrong answers I just want to know what you think. And, if at any time you would like to stop the interview, just let me know and we will stop. Ok?" Let's begin...

[Used in conjunction with Survey Form A:]

1. When you keep track of the projects you make a record book or on a recipe, what does it mean to be accurate?

2. Think of someone that is a great leader. It can be you, a friend, a President, anyone. What makes them a good leader? How do you know they are a great leader?

3. Are there other ways that can make someone a good leader?

4. Think of a time you had to compare ways of doing something. Will you please tell me about it?

5. Is there a time when one way was better than another? Will you please share with me an example?

[Used in conjunction with Survey Form B:]

1. When you disagree with someone or see others disagree with each other, how would you settle the disagreement?

2. A) Have you ever organized a group to reach a goal? How did you do that?

B) Have you ever seen someone organize a group of people to reach a goal? What kinds of skills did they have to have to get everyone to work together to reach the goal?

3. A) Have you ever been on a team? What does it mean to contribute to a team?

B) Do you know anyone that has been on a team (like a sports team)? What kinds of things does that person do to be a good teammate?

4. What are commitments? Can you give me an example of a commitment you have?

5. What does it mean to follow through on commitments you have made?

"Now do you have any questions for me? Thank you for your time! It was fun to talk with you!" 